Vidić, T. (2021). Students' school satisfaction: The role of classroom climate, self-efficacy, and engagement, International Journal of Cognitive Research in Science, Engineering and Education (IJCRSEE), 9(3), 347-357.

Original scientific paper

UDK:

316.644-057.874:37.06(497.5)

Received: July, 18.2021.

Revised: September, 12.2021.

doi: 10.23947/2334-8496-2021-9-3-347-357

Accepted: September, 25.2021.

\title{
Students' School Satisfaction: The Role of Classroom Climate, Self-efficacy, and Engagement
}

\author{
Tomislava Vidići ${ }^{*}$ \\ 1Primary school Remete, Zagreb, Croatia, e-mail: tomislava.vidic@zg.t-com.hr
}

\begin{abstract}
Students' satisfaction with school is subjective, cognitive appraisal of overall positivity of school experiences, and precisely because it represents the key aspect of children's overall perception of quality of life, it is important to find out what influences students' school satisfaction and to which extent. The goal of this research was to establish whether self-efficacy and engagement function as mediating variables in the relationship between classroom climate and students' school satisfaction. The research included 597 students from primary schools in Zagreb, Croatia. A structural equation model was designed and tested. The model testing showed that positive classroom climate has statistically significant and positive effects on self-efficacy and engagement. Furthermore, self-efficacy has a significant positive impact on explaining engagement. At the same time, negative classroom climate has a significant positive influence on engagement, which in turn contributes to the final effect on school satisfaction. The model has explained $56 \%$ of the school satisfaction variance in total.
\end{abstract}

Keywords: classroom climate, engagement, self-efficacy, school satisfaction.

\section{Introduction}

The principal aspect of students' quality of life is manifested in their satisfaction with school. How students feel in school should be equally important both to them and to the school they attend. Schools should be organized so that all students feel equally important, have the same opportunities for learning and therefore enjoy the school life. Students' satisfaction with school is an indicator of emotional and affective aspect of the quality of school life and other positive attitudes toward school, and it is linked to students' academic achievement, motivation and interests.

Based on theoretical and empirical literature in the field of subjective welfare, student school satisfaction is defined as cognitive-affective evaluation of satisfaction with school experience (Huebner, 1994). Although it is connected to other areas of subjective welfare, school satisfaction can be clearly separated from other areas of life satisfaction such as satisfaction with family, friends, living conditions, or contentment with oneself. Namely, it was proven that a student can be pleased with his/her family or living conditions, but at the same time dissatisfied with school and school experiences. The concept of the quality of school life originates from the general quality of life concept and defines student welfare from the standpoint of both positive and negative student experiences in school activities. A great number of students evaluate general life satisfaction as positive; however, if the satisfaction dimensions are observed, differences can be noticed in evaluating satisfaction with family, friends, oneself, school, and environment (Huebner et al., 2005). Students pronounce the weakest satisfaction, i.e. high dissatisfaction, with school experiences. In a research by Huebner, Drane and Valois (2000), almost one fourth of students have shown discontentment with school, and $9 \%$ of the participants have rated school experiences as „awful“. Students' perception of school environment is connected with their self-image, behavior and welfare. The importance of creating positive relationships between students and school is derived from the results of initial research in this field. The students who do not like school are underachievers and adopt forms of risky behavior (Epstein, 1981). The students who perceive school and classroom climate positively are more motivated and achieve better results (Epstein, 1981; Fraser, 1994; Voelkl, 1995). The latest longitudinal research (Löfstedt et al., 2020), which examined the trends of school pressure and school satisfaction in 32 European countries in the period between 2002 and 2018, has shown that school satisfactoin tended to increase over the focus period among boys, whereas school pressure increased among girls. Furthermore, it was proven that only a smaller proportion of the students was highly satisfied and without

"Corresponding author: tomislava.vidic@zg.t-com.hr 
school preassure. There was variability across countries, but no clear patterns associated to geographical location or differences in educational systems were apparent. Newer research (Zhou, Huebner and Tian, 2021) points to the importance of educational experiences in primary education because it is considered key to optimal development of mental health and students' academic abilities. Whether a child will attain high academic achievement is an issue influenced by many elements so it is important to understand how students perceive their school and all the factors influencing the formation of their school satisfaction.

Classroom climate represents dynamic relationships within the classroom and shows how a child experiences educational, psychological, social and physical aspects of classroom environment. In fact, it represents the psychosocial classroom climate (Fraser and Fisher, 1982). Classroom climate can be positive and negative. In general, it is considered that positive climate is dominated by satisfaction, harmony, teacher support, student cohesiveness, task orientation, student equality, and righteousness (Dorman and Adams, 2004). Relationships between students have the greatest effect on formation of positive classroom climate, i.e., they are the key factor in this process (Hattie, 2008). Apart from these relationships, positive classroom climate entails goal directedness, positive mutual relations and social support. Haertel and Walberg (1980) have established that better results in learning are achieved by students whose classrooms are dominated by cohesiveness, satisfaction, high demands, goal-orientation and organization. On the other hand, negative classroom climate is characterized by tension students feel in class, apathy and disorganization, and it is associated with poor academic achievement of students (Haertel and Walberg, 1980; Haertel et al., 1981). The synthesis of newer research has shown that classroom climate is connected with social competence, motivation and engagement, and academic achievement (Wang et al., 2020).

Self-efficacy is defined as an individual's belief that he/she is capable of performing certain actions required for attaining a specific goal, i.e. belief in possessing the ability to organize and implement actions in a way needed to achieve the planned type of effect (Bandura, 1995; 1997). Self-efficacy has proven to be the key factor connected with academic achievement, both for students and teachers, not only on an individual but also on a group level, i.e. the collective plain (Bandura, 1997). The social-cognitive theory, in whose frame the self-efficacy construct was created, considers human functioning a consequence of dynamic interaction of personal, behavioural and environmental influences. Self-regulation of learning represents active students' participation in their own process of learning through directing one's own efforts in gaining knowledge and abilities (Zimmerman, 1990; Zimmerman and Schunk, 2001). In the frame of social-cognitive theory, it is emphasized that students with self-regulated learning direct their own process of learning by setting challenging goals, using appropriate strategies and including self-regulatory influences, which motivate and steer them. Students who are self-regulated in such a way show a strong belief in their own abilities, which influences their knowledge, skills and dedication in the work done to realize their goals (Zimmerman, 1990). Self-efficacy for self-regulated learning presents a student's belief in own abilities of using various strategies in the process of learning. Such students possess the ability to plan and organize their own activities, understand and memorize class contents, disregard disruptive factors in learning, and motivate themselves to work (Zimmerman et al., 1992). Recent study (Maricutoiu and Sulea, 2019) showed a high correlation between self-efficacy and self-engagement. When students feel competent and achieve well academically, they also become more engaged in schoolwork.

Engagement is defined as a measure of students' involvement, connection and devotion to academic and social activities in school (Li and Lerner, 2013). Students' success in school, and in later life, depends on an individual's intention to use the attained knowledge and skills in the course of education (Elmore, 2009; Fredricks, Blumenfeld and Paris, 2004). Engagement should be observed as a multidimensional construct encompassing cognitive aspects and aspects of student emotions and behavior (Fredricks, Blumenfeld and Paris, 2004). The three-component engagement model entails cognitive, behavioural and emotional engagement. Cognitive engagement delineates a measure to which students perceive the importance of classes and their attitudes toward learning. Behavioural engagement can be observed at lower and higher level. Lower level is characterized by students' class attendance, while the higher level is defined by investing efforts in class. It actually describes students' willing behavior in the school context. Emotional engagement entails a student's sense of belonging to a school and respective emotions of happiness, excitement and enjoyment (Li and Lerner, 2011). It is well known that students who participate in class more show greater interest in the teaching content, identify more with school goals, are more cognitively engaged and self-regulated in learning, attain better school grades and higher overall academic achievement. A research by Barksdale et al. (Barksdale, Peters, and Corrales, 2021) proved that student learning is influenced by building relationships, availability and organisation of classroom resources, establishing classroom guidelines, and making the students feel safe and cared about in the classroom. Furthermore, newer research confirms the correlation between classroom atmosphere and 
student engagement. In Gaspard and Lauermann's research (Gaspard and Lauermann, 2021), it was shown that student and teacher perception of teacher enthusiasm and student engagement significantly shapes classroom climate.

\section{The current study}

The social-cognitive theory reflects the view of positive psychology about human functioning in which individuals strive to take control over the outcomes of their actions. Persons have beliefs that make it possible for them to influence their own thoughts, feelings, actions, social interactions and aspects of environment. At the same time, these individuals are under the influence of their own actions and social environment. According to the social-cognitive theory, strategies for increasing welfare can entail stimulation of emotional, cognitive or motivational processes and developing behavioural competences or aspects of social surroundings (Schunk and DiBenedetto, 2014). The basic idea of this research is derived from the assumption that human life is interdependent in great measure: what a person does affects the welfare of his/her environment, and vice versa. In this work, it is assumed that classroom climate is in correlation with student school satisfaction, but through the mediating role of self-efficacy and engagement (Figure 1). In other words, positive classroom climate fulfills students with belief in one's own capabilities due to which he/she manifests greater cognitive, emotional and behavioural engagement, which in turn leads to students' school satisfaction.

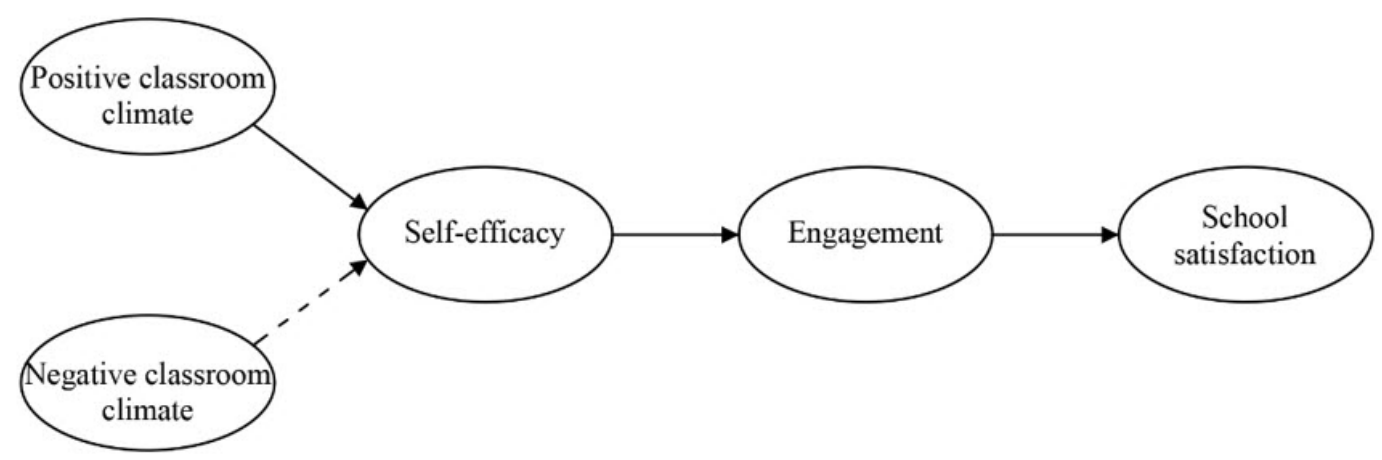

Figure 1. The hypothesed structural model tested in the present study

The aim of this research was to test whether students' self-efficacy and engagement function as mediating variables in the relationship between classroom climate and students' satisfaction with school. Accordingly, the following hypotheses were set:

(H1) Self-efficacy and engagement are mediator variables between classroom climate and students' school satisfaction.

(H2) Positive classroom climate is in direct correlation with students' self-efficacy; negative classroom climate is in negative correlation with students' self-efficacy.

$(\mathrm{H} 3)$ Self-efficacy is in direct correlation with student engagement.

(H4) Students' engagement is directly correlated with students' school satisfaction.

\section{Materials and Methods}

\section{Participants and procedure}

The data were gathered in the course of making the doctoral dissertation Classroom climate, selfefficacy, engagement, and student school satisfaction in elementary school (Vidić, 2020). The research included students of the fourth to eighth grade of primary school, for which a written consent was previously obtained from their parents. The total number of participants was 685; however, 26 participants were left out of the examination due to incompletely filled consent forms. Besides, additional 62 students were excluded from the subsequent analysis because of the outliers. The final total number of participants was 597 , out of which 292 were boys (49\%) and 305 were girls (51\%). The age of the participants was in range from 9 to 14 years, and the average age was $11.92(S D=1.49)$. The gathered data on final grades 
in Croatian, mathematics and English show that as much as $50.25 \%$ of the participants have all three As, and $17.25 \%$ of them have two As and one B. The overall average of the final grades in these three school subjects for all examinees in this research was 4.5.

\section{Measurements}

\section{Classroom climate}

For testing the perceptions of classroom climate, the questionnaire My class inventory was used (Fisher and Fraser, 1981). The questionnaire consists of 25 claims and measures five dimensions of classroom climate: satisfaction, cohesiveness (positive classroom climate), competitiveness, difficulty and friction (negative classroom climate). The factor structure was tested via main components method with ortogonal (varimax) rotation (KMO $=.920 ;$ Bartlett's sphericity test $\left.X_{\text {dfso }}^{2}=6068.00 ; p=.000\right)$, and these five factors explained $54.90 \%$ of the variance. The obtained reliability coefficient values for the friction factor is $\alpha=.843$, competitiveness $\alpha=.783$, cohesiveness $\alpha=.822$, for satisfaction $\alpha=.830$, and for the difficulty factor $a=.589$. Due to the low obtained value of reliability coefficients on the last factor, difficulty was excluded from further analyses.

\section{Self-efficacy for self-regulated learning}

To measure students' self-efficacy, one-dimensional questionnaire Self-efficacy for self-regulated learning was utilized (Zimmerman, Bandura and Martinez-Pons, 1992). The questionnaire consists of 11 claims. Factor analysis with the main components method with varimax rotation was implemented $(\mathrm{KMO}=$ 909; Bartlett's sphericity test $\chi_{\text {dif55 }}^{2}=2535.44 ; p=.000$ ). One-factor structure was obtained that explained $44.47 \%$ of the self-efficacy variance for self-regulated learning. Cronbach alpha reliability coefficient for the scale was $a=.868$.

\section{Engagement}

To measure students' engagement, The Behavioral-Emotional-Cognitive School Engagement Scale (BEC-SES) was employed (Li and Lerner, 2013). The questionnaire entails 15 claims and measures three engagement dimensions: cognitive, behavioural, and emotional engagement. Factor structure of the questionnaire was tested via the main components method with varimax rotation (KMO = .909; Bartllett's sphericity test $X_{d 1105}^{2}=3062.84 ; p=.000$ ). According to the Kaiser-Guttman criterion, three factors had characteristic roots over one, and they explained $53.30 \%$ of the variance. After the rotation, the first factor, i.e. emotional engagement, explained $20.79 \%$; the second factor, i.e. behavioural engagement, explained $16.64 \%$; and the third factor, cognitive engagement, explained $15.87 \%$ of the variance. The extracted factors match the factor solutions of the original scale. The Cronbach alpha coefficient of emotional engagement is $\alpha=.779$, of behavioural engagement $\alpha=.707$, and cognitive engagement $\alpha=.699$.

\section{School satisfaction}

The questionnaire on school satisfaction presents one dimension of the multidimensional questionnaire Multidimensional students' life satisfaction scale, MSLSS (Huebner, 1994; Huebner et al., 1998). Factor structure of the questionnaire was tested via the main components method (KMO = .871; Bartlett's sphericity test $\left.X^{2}=2122.54 ; p=.000\right)$. One-factor structure was obtained, and it explains $50.15 \%$ of the school satisfaction variance. Cronbach a coefficient is $a=.851$.

The participants evaluataed all the claims on a five-degree Likert scale, from 1 - I completely disagree, to 5 - I completely agree.

\section{Data analysis}

The correlations between classroom climate, self-efficacy, engagement and school satisfaction have been analysed using Structural Equation Model (SEM), implemented and analysed using AMOS package. In this work, exploratory factor analyses were implemented to test the measurement instruments, and then confirmatory factor analysis was utilised to test the measurement model, with testing the structural model in the end. After the implemented necessary modifications, the hypothesis on serial mediation was checked. As the data of the present study were distributed normally, the maximum likelihood estimation method was employed for SEM. Multiple fit indices - Chi-square/degrees of freedom ratio, Root-MeanSquare Error of Approximation (RMSEA), Comparative Fit Index (CFI), Tucker-Lewis Index (TLI) - were utilized to check whether the model fits the data. 


\section{Results}

Descriptive statistics (e.g., means, standard deviations, minimum, maximum, skewness, and kurtosis) are presented in Table 1. Skewness and kurtosis of all variables were examined and found to be within recommended guidelines for assuming normality, allowing for standard SEM analyses and fit indices.

Table 1.

Descriptive statistics for the observed variables $(N=597)$.

\begin{tabular}{lcccccc}
\hline Observed variable & $M$ & SD & Min & Max & Skew. & Kurt. \\
\hline Cohesiveness & 3.36 & 1.04 & 1.00 & 5.00 &,- 280 &,- 791 \\
Satisfaction & 3.57 & 0.76 & 1.60 & 5.00 &,- 320 &,- 403 \\
Friction & 2.70 & 0.91 & 1.00 & 4.80 &,- 127 &,- 700 \\
Competitiveness & 3.49 & 0.82 & 1.33 & 5.00 &,- 267 &,- 550 \\
Self-efficacy & 4.16 & 0.55 & 2.64 & 5.00 &,- 409 &,- 589 \\
Emotional engagement & 3.72 & 0.75 & 1.80 & 5.00 &,- 305 &,- 468 \\
Cognitive engagement & 4.37 & 0.50 & 3.00 & 5.00 &,- 646 &,- 305 \\
Bihevioural engagement & 3.75 & 0.56 & 2.20 & 5.00 &,- 220 &,- 334 \\
School satisfaction & 3.47 & 0.75 & 1.50 & 5.00 &,- 001 &,- 433 \\
\hline
\end{tabular}

Note. Skew. $=$ Skewness; Kurt. - Kurtosis

Two models are tested in structural modelling: the measurement and the structural model. Checking the models in this research was done in two steps: the first step tested the measurement model via confirmatory factor analysis, and the relationship between latent variables was tested in the second step. Testing of the measurement model was implemented on the whole sample, and it included five latent variables and their indicators. Item parcels were used as indicators. Latent variables and the number of respective item parcels in this research are as follows: positive classroom climate consisting of two indicators (cohesiveness and satisfaction); negative classroom climate entailing two indicators (competitiveness and tension); self-efficacy divided into three indicators; engagement, also comprised of three indicators (emotional, cognitive and behavioural engagement); school satisfaction divided into two indicators. The model showed a good fit to the empirical data: $X^{2}=149.89, X^{2 / d f}=3.57, C F I=.96, T L I=$ $.93, \mathrm{RMSEA}=.07$. Due to a large sample, the Chi-square test is not satisfactory, while the other indicators show the fitness of the model so it was accepted.

The correlations between latent variables are presented in Table 2. The correlations between latent variables show the expected relationships. Hence, negative classroom climate is negatively correlated to all other variables. Positive classroom climate is positively correlated to self-efficacy, engagement and school satisfaction. The greatest correlation was found between school satisfaction and engagement, i.e. self-efficacy and engagement. Expectedly, the highest negative correlation was proven between positive and negative classroom climate.

Table 2.

Correlations among the observed variables in the study.

\begin{tabular}{lcccc}
\hline & 2 & 3 & 4 & 5 \\
\hline 1. Positive classroom climate &,$- 85^{\star \star \star}$ &, $37^{\star \star \star}$ &, $68^{\star \star \star}$ &, $44^{\star \star \star}$ \\
2. Negative classroom climate & &,$- 25^{\star \star \star}$ &,$- 41^{\star \star \star}$ &,$- 16^{\star \star}$ \\
3. Self-efficacy & & &, $75^{\star \star \star}$ &, $57^{\star \star \star}$ \\
4. Engagement & & & &, $81^{\star \star \star}$ \\
5. School satisfaction & & & & \\
\hline
\end{tabular}

Note. ${ }^{*} p<.05 ;{ }^{* *} p<.01 ;{ }^{* \star *} p<.001$

Considering that the final structural model is based on the hypothesis of serial mediation wherein self-efficacy mediates between classroom climate and engagement, in turn influencing overall school satisfaction, the mediation effect of self-efficacy was initially shown in the connection between two aspects 
of classroom climate (positive and negative) and engagement (Figure 2).

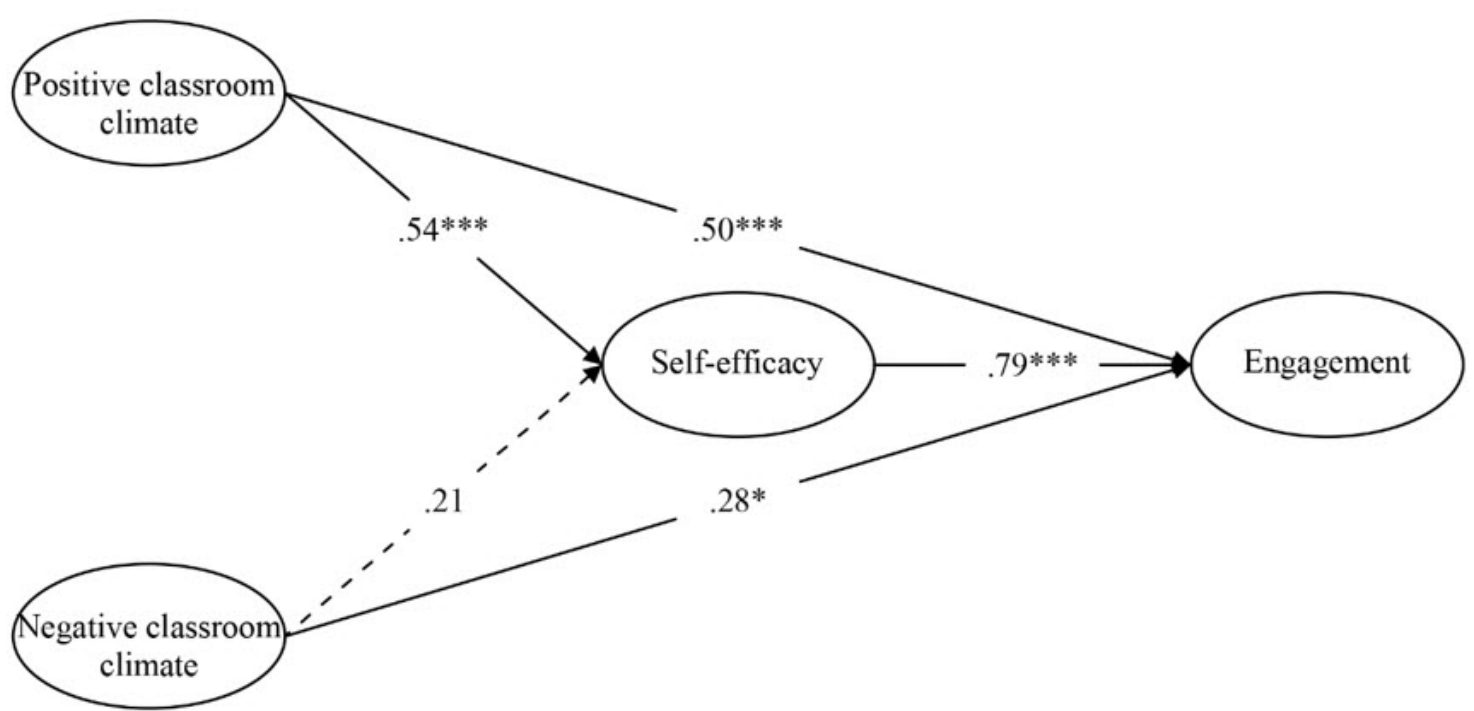

Figure 2. The mediation effect of self-efficacy in the relationship between classroom climate and engagement

$$
{ }^{*} p<.05 ;{ }^{* *} p<.01 ;{ }^{* * *} p<.001
$$

In the course of testing the path between classroom climate as a predictor, self-efficacy as mediator and engagement as criterion, the obtained values indicated a significant contribution of positive classroom climate to self-efficacy and direct and significant positive contribution to engagement. Negative classroom climate has no statistically significant contribution to self-efficacy, but its effect on engagement is statistically significant and positive, contrary to expectations. Finally, the contribution of self-efficacy, as mediator, to engagement is also statistically significant, positive and proportionally high. The results are congruent with the expectations, apart from the result that points to a positive effect of negative classroom climate on student engagement. The cause of this finding can be in the fact that a part of friction or competitiveness variance has, apart from the negative, a positive correlation to engagement aspects. In this research, it is visible that competitiveness is negatively associated with self-efficacy and emotional and cognitive engagement, while it has no significant correlation with emotional engagement. This means that bigger part of friction is still negatively correlated with these constructs. In the mediation analysis, if a certain latent variable contains a part of the covariance of the opposite sign of expected, depending on other relationships in the model, that covariance can be increased, i.e. expressed, and therefore create a significant effect. Hence, although the total correlation of negative climate with overall engagement is negative, a part of the negative climate variance is in positive correlation with one part of the engagement variance. Regarding other variables in the analysis (in this case, primarily positive classroom climate, due to high negative intercorrelation), a suppressive effect takes presence - the covariance with a positive climate neutralizes the significant negative contribution to self-efficacy, but leaves residual variance of the opposite sign, which becomes significant in the contribution to engagement. Although it could be deliberated, based on such result, that negative classroom climate is redundant in the model, it actually contributes to it significantly with its effect to engagement and with the increase in covariance between positive climate and included mediators. The right interpretation of such results is that positive classroom climate positively and directly influences self-efficacy, and it has an indirect effect on engagement when negative classroom climate is kept under control.

Furthermore, analysis of the path foreseen in the research hypotheses is presented. According to these hypotheses, self-efficacy realizes the effect on overall school satisfaction only through engagement. The results are presented in Figure 3.

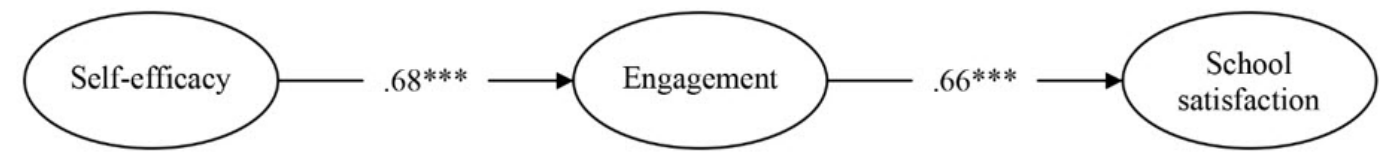

Figure 3. The path analysis - effects of self-efficacy via engagement on school satisfaction. ${ }^{*} p<.05 ;{ }^{* *} p<.01 ;{ }^{* * *} p<.001$ 
Both effects are statistically significant and positive. Self-efficacy contributes to engagement while engagement also shows a positive effect on school satisfaction. In other words, self-efficacy exerts the effect on overall school satisfaction via student engagement.

With regard to the results showing significant contributions of positive classroom climate to the mediators and school satisfaction, whereas negative climate had no effects, except in the case of engagement, such structure was created in the final model with all present effects of positive climate, whereas negative climate only had an effect on engagement. From such final structural model, presented in Figure 4, it is visible that positive classroom climate has statistically significant and positive effects on self-efficacy and engagement. However, after introducing mediators into the analysis, the direct effect of positive classroom climate on school satisfaction has become close to zero and statistically insignificant. It shows that full mediation of self-efficacy and engagement in effecting positive classroom climate and school satisfaction took place. Self-efficacy also had a significant positive effect on explaining engagement. At the same time, negative classroom climate had a significant positive contribution to engagement, which in turn emphasized the final effect on school satisfaction. In the model, age was kept under control, i.e. students' grade. The model has explained $56 \%$ of the satisfaction with school variance in total.

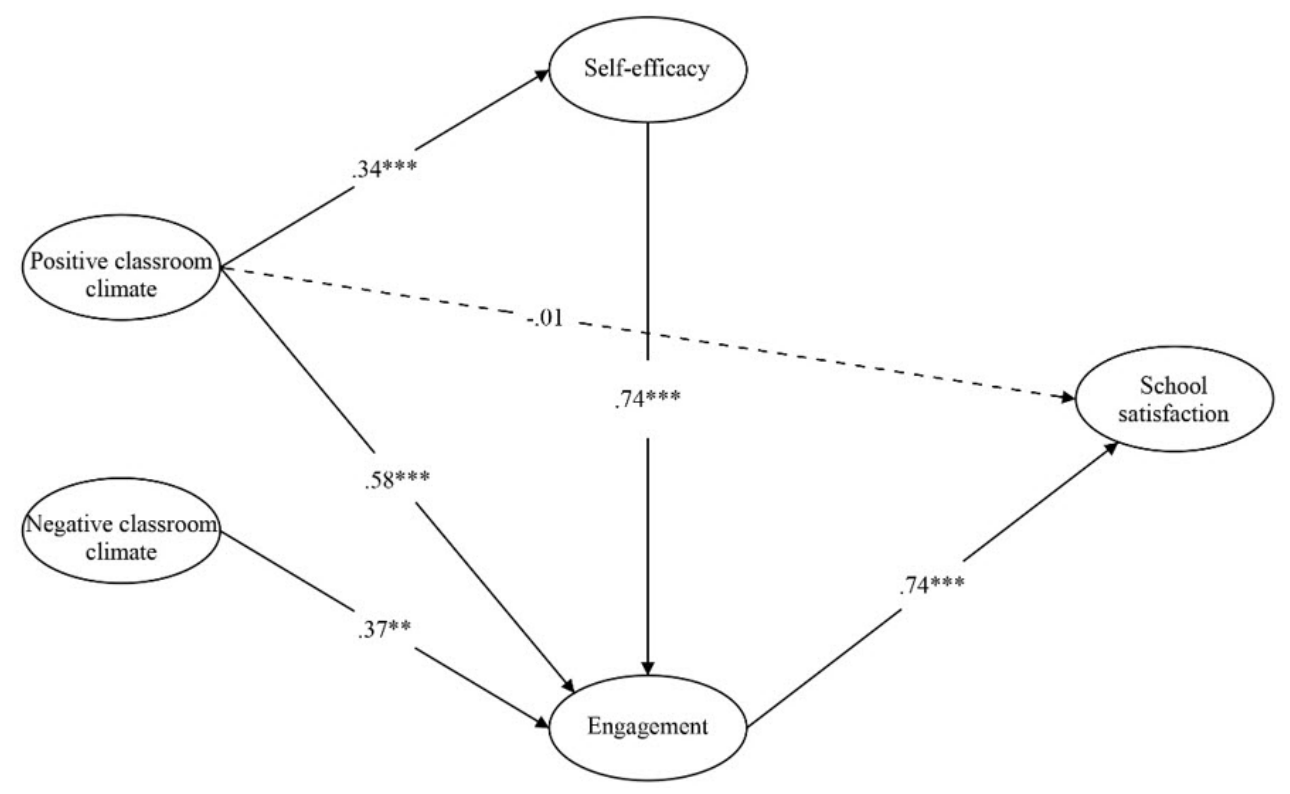

Figure 4. The final structural model for the whole sample.

${ }^{*} p<.05 ;{ }^{* *} p<.01 ;{ }^{* * *} p<.001$

It was established that the model fits the data. Chi-square test, which is one of the most frequently used indicators of the model's fitness, has proven to be statistically significant $\left(X^{2}=121.82 ; \mathrm{df}=50 ; p\right.$ $<.001$ ). Such result points to insufficient data's fitness for the model; however, the drawback of this test is that it is almost always significant for models tested on large samples. Therefore, a correction was done regarding the number of freedom degrees. The obtained value $\left(X^{2 / d f}=2.4\right)$ is smaller than the recommended value $X^{2 / d f} \leq 5$ and indicates the measurment model's fitness for the data. Furthermore, the average standard residual mistake (RMSEA) is.049, which points to a good fit. The CFI was.97, and TLI .96 , which are satisfactory fit indices.

\section{Discussions}

As was assumed, the final model of this research has shown that positive classroom climate has statistically significant and positive effects on self-efficacy and engagement. Previous insight on the matter indicates correlation between self-efficacy, behavior and environment (Bandura, 1997; Schunk and DiBenedetto, 2014). Highly self-efficient students are motivated to learn, engaged and create efficient learning environment. At the same time, self-efficacy is under the influence of external factors such as, for example, feedback from teachers and social comparisons to peers. Individuals receive much information about their own abilities through cognizance of abilities of others. It is a known fact that peers influence self-efficacy through observing experiences of others, and such comparison with others is especially 
emphasized among children and adolescents primarily because they find themselves in unknown situations that are alike. Observing similar students can raise a person's confidence in one's own abilities because it provides the feedback "if they can do it, so can l". Of course, the opposite also applies. A student who witnesses failure of another similar student can convince himself that he is not capable of successful task performance. However, relationships between students are set up on the principle of resemblance, i.e. students are more inclined to bond with other students with whom they share the same characteristics, interests and likeness, and with time, they become even more similar. Their conversations influence their activities and choices, causing them to make similar decisions, and such cohesion contributes to selfefficacy and motivation. It was proven even before that students' satisfaction with the class they attend contributes to their desire to learn and persistence in work (Asakereh and Dehghannezhad, 2015). The emotional component of classroom climate was proven as a contribution to students' achievement if their needs for bonding, competence and autonomy are met (Connell and Wellborn, 1993). The teachers who create a positive climate and stimulate student interaction at the same time encourage students to persist in learning (Skinner and Belmont, 1993). Consequently, students will be more engaged in school (Patrick, Ryan and Kaplan, 2007; Wentzel, 1997).

Self-efficacy is directly linked to engagement, which entirely confirms the hypothesis in this research. It can be assumed that a student's belief in her abilities advances the amount of invested effort and industry in performing school tasks. It is known from before that highly self-efficient individuals invest increased effort and do not give up on completing tasks even if they are faced with more complexed tasks or problems. On the contrary, individuals with low self-efficacy are more inclined to avoid or give up work when confronted with issues that are more complex. Along the same lines, the implementation of more in-depth learning strategies, as the main feature of cognitive engagement, is linked to self-efficacy. These results are in line with the learnings of previous research, which show that highly self-efficient students use diverse cognitive, metacognitive and self-regulatory learning strategies more frequently (Pintrich, 1999) and generally display greater engagement (Appleton et al., 2006; 2008). Students who are assured of their own abilities try to think in different ways in order to solve problems they are faced with and are therefore more cognitively engaged. Similarly, it is more probable that highly self-efficient students will perceive positive emotions such as pride or happiness concerning school and therefore become emotionally more engaged (Linnenbrink and Pintrich, 2003).

Despite the expectation that positive classroom climate would have a direct effect on students' school satisfaction, this research proved a direct effect on students' school satisfaction only of self-efficacy and engagement. A greater body of research heretofore indicates that cohesion between peers and their positive attitudes towards school influence school satisfaction and life in general (Epstein, 1981), which was also assumed in this research. However, it seems that positive classroom climate is indispensable in forming self-efficacy and engagement of students, and only consequently will such students be content with school. It is possible that the participants in this reserach perceive school as a place to learn and work on school tasks and that, in order for them to be satisfied with school, only positive classroom climate will not suffice, but they need to know they are capable of performing school chores and perservere in doing so in order to feel satisfied. The reserach done by Bubić and Goreta (2015) found similar results. The contribution of social integration to overall school satisfaction by mediation of the perceived academic control of students was proven. It seems that starting and maintaining good social relationships with other students is not sufficient for increasing school satisfaction in students who feel they cannot control their academic achievement. However, there is little research implemented which included the influence of environmental factors on students' school satisfaction. A qualitative research by Lam, Yeung and Yuen (2018) has shown that Chinese students, who achieve high results and at the same time possess high cognitive abilities, show contentment with school if personal (goal-directedness, self-discipline and selfregulation) and environmental influences (positive relations between students and teachers, emotional and instrumental support from peers, support from parents) are realized. Besides, while Chinese culture entails a belief that only hard work leads to success, the examined students stressed they had positive attitudes about school only if they had peer support. It is known that students' school satisfaction should also be observed through the cultural dimension: while in western cultures external factors such as teacher support and availability of opportunities and means in and out of school have significant influence on students' school satisfaction (Subotnik, Olszewski-Kubilius and Worrell., 2011), Lam, Yeung and Yuen (2018) research emphasized strong relationships with teachers, students and family.

The ideal classroom is ruled by positive classroom climate; in such classroom, students are satisfied and mutually related. Negative classroom climate is dominated by friction, competition and difficulty. According to these assumptions, the hypotheses of this research were formulated. However, the final structural model shows that negative classroom climate has a significant positive contribution 
to engagement, which in turn contributes to the final effect on school satisfaction. This might be due to students being more engaged in a competitive environment and put more effort in the work. It is generally considered that competition within a group or a class is a negative characteristic possibly leading to series of unwanted phenomena because competitive classroom climate places emphasis on marks and is less directed to learning, i.e. gaining knowledge and skills. When a class is characterized by competitive climate, students are directed to achieving goals, constantly comparing with others. Thus, their goal is to attain positive evaluation from their environment and avoid failure. When considering a class that does not stress competition, students have a chance to be more directed to learning. Competitiveness is defined as a general personality trait according to which an individual has a maladjusted desire to win, at any cost (Horney, 1937, as cited in Klein and Newby, 2017). In classroom ruled by competitive climate, students can perceive their own success as failure if their performance is not pointed out as an example of excellence. Considering that experience of achievement is an important source of self-efficacy, precisely such perception of poor success or failure, even among accomplished students, can lead to weaker self-efficacy. On the other hand, in non-competitive classrooms students are not burdened with the need to stand out and are therefore more inclined to find similarities than differences to other students when compared, and in such a way evaluate their own performance more positively. However, this research found that students do not perceive negative sides of competition. It is possible they are more directed to achieving goals, and they feel they have attained them through assigned marks. Namely, as much as $50,25 \%$ of the participants have As in Croatian language, mathematics and English language, and additional $17,25 \%$ have one $B$ and two $A$ s. It is possible that precisely such high final marks made students insensitive to competitve classroom climate because they felt they had been successful and realised the assigned tasks. One part on authors underline that competitive classroom climate is not necessarily negative, but also has positive effects. For example, Ryckman et al. (1997) consider such climate creates the desire for personal development. The motivation to succeed is greater in such students (Smither and Houston, 1992), they are more inclined to behaviors leading them to success (Bing, 1999), and they are more involved in the teaching process (Shimotsu-Dariol, Mansson and Myers 2012). Therefore, a positive direct effect of negative classroom climate on engagement found in this research should be observed in this context.

\section{Conclusions}

The principal theoretical contribution of this research is verification of the correlation between classroom climate and self-efficacy and engagement, and their effect on students' school satisfaction. According to the social-cognitive theory, whose frame entails the basic idea of this research, strategies for improving individual benefits can be realized through influence on emotional, cognitive and motivational processes and improvement of behavioural competence or environmental aspects. It was assumed in this research that positive classroom climate would be directly correlated with self-efficacy, directly and indirectly with students' engagement, which would in turn lead to students' satisfaction with school. The verification of the assumed model by structural modelling has confirmed previous hypotheses. It was found that students who perceived positive classroom climate were characterized by greater self-efficacy and engagement and were more satisfied with school. At the same time, positive classroom climate directly influenced students' engagement so they felt satisfied with school. Regardless of this research having examined only dimensions of students' satisfaction with their class and cohesion, the results are in line with previous research that included additional dimensions of positive classroom climate. The basic assumption that students who feel good in their class would be diligent and more devoted to school work, which would in turn effect their school satisfaction, has proven to be correct. Although it was not presupposed, the final model indicated direct influence of negative classroom climate on engagement, and consequently on students' school satisfaction. Therefore, the results showed that competitive environment did not disturb students in greater measure, and that they were nevertheless engaged in school assignments and satisfied with school. However, the aforementioned leads to the conclusion that classroom climate is a whole with all its advantages and drawbacks, and if negative characteristics of such climate do not prevail over the good ones, students will get the chance for self-realization: they will be self-efficient, engaged and satisfied with school.

\section{Acknowledgements}

I would like to thank all the people who contributed to the realization of this study. 
Vidić, T. (2021). Students' school satisfaction: The role of classroom climate, self-efficacy, and engagement, International Journal of Cognitive Research in Science, Engineering and Education (IJCRSEE), 9(3), 347-357.

\section{Conflict of interests}

The author declares no conflict of interest.

\section{References}

Appleton, J. J., Christenson, S. L., \& Furlong, M. J. (2008). Student engagement with school: Critical conceptual and methodological issues of the construct. Psychology in the Schools, 45(5), 369-386. https://doi.org/10.1002/pits.20303

Appleton, J. J., Christenson, S. L., Kim, D., \& Reschly, A. L. (2006). Measuring cognitive and psychological engagement: Validation of the Student Engagement Instrument. Journal of school psychology, 44(5), 427-445. https://doi. org/10.1016/j.jsp.2006.04.002

Asakereh, A., \& Dehghannezhad, M. (2015). Student satisfaction with EFL speaking classes: Relating speaking self-efficacy and skills achievement. Issues in Educational Research, 25(4), 345-363. Retrieved from http://www.iier.org.au/iier25/ asakereh.html

Bandura, A. (1995). Exercise of personal and collective efficacy in changing societies. In A. Bandura (Ed.), Self-efficacy in Changing Societies (pp. 1-45). Cambridge University Press.

Bandura, A. (1997). Self-efficacy: The exercise of control. Freeman.

Barksdale, C., Peters, M. L., \& Corrales, A. (2021). Middle school students' perceptions of classroom climate and its relationship to achievement. Educational Studies, 47(1), 84-107. https://doi.org/10.1080/03055698.2019.1664411

Bing, M. N. (1999). Hypercompetitiveness in academia: Achieving criterion-related validity from item context specificity. Journal of Personality Assessment, 73(1), 80-99. https://doi.org/10.1207/S15327752JPA730106

Bubic, A., \& Goreta, I. (2015). Akademske i socijalne odrednice općeg zadovoljstva školom [Academic and social determinants of general school satisfaction]. Psihologijske teme, 24(3), 473-493. https://hrcak.srce.hr/149105

Connell, J. P. \& Wellborn, J. G. (1993). Competence, autonomy, and relatedness: A motivational analysis of self-system processes. In M. R. Gunnar \& L. A. Sroufe (Eds.), Minnesota symposia on child psychology, Vol. 23. (pp. 43-77). Lawrence Erlbaum.

Dorman, J., \& Adams, J. (2004). Associations between students' perceptions of classroom environment and academic efficacy in Australian and British secondary schools. Westminster Studies in Education, 27(1), 69-85. https://doi. org/10.1080/0140672040270106

Elmore, R. F. (2009). Schooling adolescents. In R. M. Lerner \& L. Steinberg (Eds.), Handbook of adolescent psychology (3rd ed.; pp. 193-227). John Wiley \& Sons.

Epstein, J. L. (1981). The quality of school life. D.C. Heath/Lexington Books.

Fisher, D. L., \& Fraser, B. J. (1981). Validity and Use of the My Class Inventory. Science education, 65(2), 145-56. https://doi. org/10.1002/sce.3730650206

Fraser, B. J. (1994). Research on classroom and school climate. In D. L. Gabel (Ed.), Handbook of Research on Science Teaching and Learning (pp. 493-541). Macmillan.

Fraser, B. J., \& Fisher, D. L. (1982). Predicting students' outcomes from their perceptions of classroom psychosocial environment. American Educational Research Journal, 19(4), 498-518. https://doi.org/10.3102/00028312019004498

Fredricks, J. A., Blumenfeld, P. C., \& Paris, A. H. (2004). School engagement: Potential of the concept, state of the evidence. Review of educational research, 74(1), 59-109. https://doi.org/10.3102/00346543074001059

Gaspard, H., \& Lauermann, F. (2021). Emotionally and motivationally supportive classrooms: A state-trait analysis of lessonand classroom-specific variation in teacher-and student-reported teacher enthusiasm and student engagement. Learning and Instruction, 75, 101494. https://doi.org/10.1016/j.learninstruc.2021.101494

Haertel, G. D., \& Walberg, H. J. (1980). Investigating an educational productivity model. Evaluation in Education, 4, 103-104. https://doi.org/10.1016/0191-765X(80)90032-4

Haertel, G. D., Walberg, H. J., \& Haertel, E. H. (1981). Socio-psychological environments and learning: A quantitative synthesis. British educational research journal, 7(1), 27-36. https://doi.org/10.1080/0141192810070103

Hattie, J. (2008). Visible learning: A synthesis of over 800 meta-analyses relating to achievement. Routledge. https://doi. org/10.4324/9780203887332

Huebner, E. S. (1994). Preliminary development and validation of a multidimensional life satisfaction scale for children. Psychological assessment, 6(2), 149. https://doi.org/10.1037/1040-3590.6.2.149

Huebner, E. S., Drane, W., \& Valois, R. F. (2000). Levels and demographic correlates of adolescent life satisfaction reports. School Psychology International, 21(3), 281-292. https://doi.org/10.1177/0143034300213005

Huebner, E. S., Laughlin, J. E., Ash, C., \& Gilman, R. (1998). Further validation of the multidimensional students' life satisfaction scale. Journal of Psychoeducational Assessment, 16(2), 118-134. https://doi.org/10.1177/073428299801600202

Huebner, E. S., Valois, R. F., Paxton, R. J., \& Drane, J. W. (2005). Middle school students' perceptions of quality of life. Journal of Happiness studies, 6(1), 15-24. https://doi.org/10.1007/s10902-004-1170-x

Klein, R. \& Newby, J. (2017). Competitiveness. In T. S. V. Zeigler-Hill \& T. K. Shackelford (Eds.), Encyclopedia of personality and individual differences (pp. 1-5). Springer. https://doi.org/10.1007/978-3-319-28099-8_1056-1

Lam, C. S. C., Yeung, P. P., \& Yuen, M. (2018). Personal and Environmental Factors Affecting Hong Kong High-Ability Students' School Satisfaction. Journal of Psychologists and Counsellors in Schools, 28(2), 166-184. https://doi.org/10.1017/ jgc.2017.18

Li, Y., \& Lerner, R. M. (2011). Trajectories of school engagement during adolescence: implications for grades, depression, delinquency, and substance use. Developmental psychology, 47(1), 233. https://doi.org/10.1037/a0021307

Li, Y., \& Lerner, R. M. (2013). Interrelations of behavioral, emotional, and cognitive school engagement in high school students. Journal of Youth and Adolescence, 42(1), 20-32. https://doi.org/10.1007/s10964-012-9857-5

Linnenbrink, E. A., \& Pintrich, P. R. (2003). The role of self-efficacy beliefs instudent engagement and learning intheclassroom. Reading \&Writing Quarterly, 19(2), 119-137. https://doi.org/10.1080/10573560308223

Löfstedt, P., García-Moya, I., Corell, M., Paniagua, C., Samdal, O., Välimaa, R., ... \& Rasmussen, M. (2020). School satisfaction 
and school pressure in the WHO European region and North America: An analysis of time trends (2002-2018) and patterns of co-occurrence in 32 countries. Journal of adolescent health, 66(6), S59-S69. https://doi.org/10.1016/j. jadohealth.2020.03.007

Maricuțoiu, L. P., \& Sulea, C. (2019). Evolution of self-efficacy, student engagement and student burnout during a semester. A multilevel structural equation modeling approach. Learning and Individual Differences, 76, 101785. https://doi. org/10.1016/j.lindif.2019.101785

Patrick, H., Ryan, A. M., \& Kaplan, A. (2007). Early adolescents' perceptions of the classroom social environment, motivational beliefs, and engagement. Journal of educational psychology, 99(1), 83-98. https://doi.org/10.1037/0022-0663.99.1.83

Pintrich, P. R. (1999). The role of motivation in promoting and sustaining self-regulated learning. International journal of educational research, 31(6), 459-470. https://doi.org/10.1016/S0883-0355(99)00015-4

Ryckman, R. M., Libby, C. R., van den Borne, B., Gold, J. A., \& Lindner, M. A. (1997). Values of hypercompetitive and personal development competitive individuals. Journal of personality assessment, 69(2), 271-283. https://doi.org/10.1207/ s15327752jpa6902 2

Schunk, D. H. \& DiBenedetto, M. K. (2014). Academic self-efficacy. U Furlong, M. J. Furlong, R. Gilman \& E. S. Huebner, Handbook of positive psychology in schools (pp. 115-130). New York, NY: Routledge.

Schunk, D. H. (1991). Self-efficacy and academic motivation. Educational psychologist, 26(3-4), 207-231. https://doi.org/10.1 080/00461520.1991.9653133

Shimotsu-Dariol, S., Mansson, D. H., \& Myers, S. A. (2012). Students' academic competitiveness and their involvement in the learning process. Communication Research Reports, 29(4), 310-319. https://doi.org/10.1080/08824096.2012.723643

Skinner, E. A., \& Belmont, M. J. (1993). Motivation in the classroom: Reciprocal effects of teacher behavior and student engagement across the school year. Journal of educational psychology, 85(4), 571. https://doi.org/10.1037/00220663.85.4.571

Smither, R. D., \& Houston, J. M. (1992). The nature of competitiveness: The development and validation of the competitiveness index. Educational and Psychological Measurement, 52(2), 407-418. https://doi.org/10.1177/0013164492052002016

Subotnik, R. F., Olszewski-Kubilius, P., \& Worrell, F. C. (2011). Rethinking giftedness and gifted education: A proposed direction forward based on psychological science. Psychological science in the public interest, 12(1), 3-54. https://doi. org/10.1177/1529100611418056

Vidić, T. (2020). Razredno-nastavno ozračje, samoučinkovitost, angažiranost i zadovoljstvo školom učenika u osnovnoj školi [Classroom climate, self-efficacy, engagement, and student school satisfaction in elementary school]. [Unpublished doctoral dissertation]: Faculty of Teacher Education, University of Zagreb.

Voelkl, K. E. (1995). School warmth, student participation, and achievement. The journal of experimental education, 63(2), 127-138. https://doi.org/10.2307/20152443

Wang, M. T., Degol, J. L., Amemiya, J., Parr, A., \& Guo, J. (2020). Classroom climate and children's academic and psychological wellbeing: A systematic review and meta-analysis. Developmental Review, 57, 100912. https://doi.org/10.1016/j. dr.2020.100912

Wentzel, K. R. (1997). Student motivation in middle school: The role of perceived pedagogical caring. Journal of educational psychology, 89(3), 411. https://doi.org/10.1037/0022-0663.89.3.411

Zhou, J., Huebner, E. S., \& Tian, L. (2021). Co-developmental trajectories of psychological need satisfactions at school: Relations to mental health and academic functioning in Chinese elementary school students. Learning and Instruction, 74, 101465. https://doi.org/10.1016/j.learninstruc.2021.101465

Zimmerman, B. J. (1990). Self-regulated learning and academic achievement: An overview. Educational psychologist, 25(1), 3-17. https://doi.org/10.1207/s15326985ep2501_2

Zimmerman, B. J., \& Schunk, D. H. (Eds.). (2001). Self-regulated learning and academic achievement: Theoretical perspectives. Routledge.

Zimmerman, B. J., Bandura, A., \& Martinez-Pons, M. (1992). Self-motivation for academic attainment: The role of selfefficacy beliefs and personal goal setting. American educational research journal, 29(3), 663-676. https://doi. org/10.3102/00028312029003663 